\title{
High frequency of tumor cells with nuclear Egr- I protein expression in human bladder cancer is associated with disease progression
} Frederikke Lihme Egerod*1,2, Annette Bartels², Niels Fristrup ${ }^{3}$, Michael Borre ${ }^{4}$, Torben F Ørntoft ${ }^{3}$, Martin B Oleksiewicz ${ }^{5}$, Nils Brünner ${ }^{2}$ and Lars Dyrskjøt ${ }^{3}$

\author{
Address: ${ }^{1}$ Cell and Antibody Analysis, Novo Nordisk A/S, Novo Nordisk Park, DK-2760 Maaloev, Denmark, ${ }^{2}$ Section of Pathobiology, Department \\ of Veterinary Disease Biology, Dyrlægevej 88, DK-1870 Frederiksberg C, Denmark, ${ }^{3}$ Molecular Diagnostic Laboratory, Department of Molecular \\ Medicine, Aarhus University Hospital, Skejby, Science Center Skejby, Brendstrupgaardsvej 21, DK-8200 Aarhus N, Denmark, ${ }^{4}$ Department of \\ Urology, Aarhus University Hospital, Skejby, DK-8200 Aarhus N, Denmark and ${ }^{5}$ Molecular Microbiology, Intercell AG, Campus Vienna Biocenter \\ 3, 1030 Vienna, Austria \\ Email: Frederikke Lihme Egerod* - fle@life.ku.dk; Annette Bartels - anba@life.ku.dk; Niels Fristrup - nfr@studmed.au.dk; \\ Michael Borre - borre@ki.au.dk; Torben F Ørntoft - orntoft@ki.au.dk; Martin B Oleksiewicz - moleksiewicz@intercell.com; \\ Nils Brünner - nbr@life.ku.dk; Lars Dyrskjøt - lars@ki.au.dk \\ * Corresponding author
}

Published: 30 October 2009

BMC Cancer 2009, 9:385 doi:10.1186/1471-2407-9-385

This article is available from: http://www.biomedcentral.com/147/-2407/9/385

(c) 2009 Egerod et al; licensee BioMed Central Ltd.

This is an Open Access article distributed under the terms of the Creative Commons Attribution License (http://creativecommons.org/licenses/by/2.0), which permits unrestricted use, distribution, and reproduction in any medium, provided the original work is properly cited.

\begin{abstract}
Background: Egr-I (early growth response-I transcription factor) has been proposed to be involved in invasion and metastasis processes of human bladder cancer, but Egr-I protein expression levels in human bladder cancer have not been investigated. In the present study we investigated the expression levels of Egr-I protein in early stages of human bladder cancer and correlated it to later progression.
\end{abstract}

Methods: Expression of Egr-I protein in human bladder cancer was examined by immunohistochemistry, on a tissue microarray constructed from tumors from 289 patients with non-muscle invasive urothelial bladder cancer.

Results: The frequency of tumor cells with nuclear Egr-I immunolabelling correlated to bladder cancer stage, grade and to later progression to muscle-invasive bladder cancer (T2-4). Stage TI tumors exhibited significantly higher frequencies of tumor cells with nuclear Egr-I immunolabelling than Ta tumors $(P=0.00 I)$. Furthermore, Kaplan-Meier survival analysis showed that a high frequency of tumor cells with nuclear Egr-I immunolabelling was significantly associated with a higher risk of progression to stage T2-4 (log-rank test, $P=0.035$ ). Tumor cells with nuclear Egr-I immunolabelling were found to localize at the tumor front in some of the tumor biopsies.

Conclusion: The results from this study support a potential involvement of Egr-I in the progression from non-muscle invasive bladder cancers to muscle invasive bladder cancer. 


\section{Background}

Human bladder cancer is the forth most common malignancy in men, and the tenth most common in women [1]. The majority of malignant bladder tumors are urothelial cell carcinomas evolved from the epithelial lining of the bladder wall (urothelium). These tumors can be further divided into papillary, solid and carcinoma in situ (CIS) lesions. Papillary tumors are the most common type, they tend to grow slowly. Solid tumors are less frequent and more aggressive and infiltrate the muscular layer of the bladder wall. CIS is a lesion involving only the inner lining of the bladder. Bladder tumors are classified according to the depth of invasion: non-invasive $\mathrm{Ta}$, and laminapropria invasive but not muscle-invasive $\mathrm{T} 1$ tumors, and muscle-invasive T2-4 tumors. More than $60 \%$ of the Ta tumors recur, which makes this tumor type mainly responsible for the high prevalence rate. About $40 \%$ of the patients experience multiple recurrences, which has a significant impact on the quality of life.

Studies in urothelial carcinoma cells have demonstrated different gene expression profiles in non-muscle invasive and muscle invasive tumors and molecular classifiers of urothelial cell carcinoma outcome have been identified [2]. Furthermore, different biomarker proteins have been investigated to diagnose and prognosticate bladder cancers [3-6]. However, more information about different molecular subtypes and molecular pathways of early stage bladder tumors might ultimately facilitate prediction of disease outcome and treatment response.

Egr-1 (early growth response factor 1, Zif268, NGFI-A, TIS8, Krox-24) has been proposed to be involved in the invasion and metastasis processes of human bladder cancer $[7,8]$. In both bladder and prostate cancer Egr- 1 is shown to regulate the expression of heparanase and hyaluronidase, which are implicated in the metastatic spread of cancer cells [8-10]. Egr-1 is a zinc finger transcription factor involved in cellular responses to mitogens, growth factors and stress stimuli. Egr-1 has also been proposed to be an early biomarker in rat urinary bladder cancer induced by dual-acting PPAR agonists [11]. Egr-1 is induced by epidermal growth factor (EGF) and has been shown to correlate to EGF receptor (EGFr) levels in bladder tumors [7]. The EGFr is a recognized bladder tumor marker and high levels of EGFr are associated with non-papillary, high-grade invasive tumors [12].

To our knowledge only the Egr-1 mRNA but not the protein expression levels in human bladder cancer have been previously investigated [8]. In the present study we investigated the expression levels of Egr-1 protein in early stages of human bladder cancer and correlated it to later progression.
The REMARK recommendations were followed when feasible [13].

\section{Methods \\ Patient information}

Bladder tumor biopsies were obtained with informed written consent from the patients. The study was approved by The Scientific Ethical Committee of the County of Aarhus (1994/2920). All tumors selected for this study were primary urothelial tumors, stage Ta or T1. The patient material was collected from 1979 to 2007 . Median follow-up time was 74 months (range 1-232 months). The patient follow-up was from the first diagnostic resection to the most recent cystoscopy. In case of death before progression or before a five year follow-up without progression, the patients were excluded from the study. The event of progression to muscle invasive bladder cancer was verified by pathological examination. Patients who underwent cystectomy before pathological evidence of progression were excluded from the study. Two patients received chemotherapy during the course of the disease and 56 patients received bacillus Calmette-Guérin (BCG) immunotherapy. 101 patients had concomitant CIS during follow-up and of these 38 patients received BCG immunotherapy.

\section{Biological material}

At the Institute of Pathology, Aarhus University Hospital, Denmark, formalin fixed paraffin embedded urothelial tumor blocks were selected for this study. A total of 289 patients with primary, non-muscle invasive urothelial tumors (182 pTa, 101 pT1, 6 CIS) fulfilled the inclusion criteria for the study; 118 tumors progressed to muscle invasive bladder cancer (pT2-T4) during follow-up. The remaining 171 patients were followed for at least five years and none showed progression to muscle invasive bladder cancer.

The original Haematoxylin-Eosin (HE) stained sections were reviewed by an experienced uropathologist who reevaluated the stage and grade of each tumor blinded to the original diagnosis. Grading was performed according to WHO 2004 classification. The original slides for tumors diagnosed before 1997 were not available, and consequently new HE stained sections were made and evaluated by the same uropathologist, who also identified the tumor regions of each paraffin embedded bladder cancer for the following tissue microarray construction. Tissue samples of normal urothelium were taken from persons with no history of bladder tumors, but who suffered from unknown bladder pathologies that indicated bladder biopsy.

Sections of paraffin embedded human prostate cancer specimens $(n=3)$ (a kind gift from the Pathology Depart- 
ment, Rigshospitalet, Denmark) were used as positive controls for Egr-1 immunolabelling, as Egr-1 is found overexpressed in the majority of human prostate cancers [14-17].

\section{Tissue microarray construction}

One biopsy ( $0.6 \mathrm{~mm}$ cores) from every tumor was taken from the area marked by the uropathologist and placed in the recipient paraffin block using a custom-made precision instrument (manual tissue microarrayer 1, Beecher Instruments Inc., Sun Prairie, WI, USA). This was done according to the method developed by Kononen [18].

\section{Antibodies}

Egr-1 rabbit monoclonal antibody (Cell Signaling Technology, California, USA, catalogue number 4153) was used at 1:750 dilution.

Biotinylated secondary antibody, polyclonal goat antirabbit (Dako A/S, Denmark, catalogue number E0432) was used at 1:2000 dilution.

\section{Immunohistochemistry}

The TMA was dewaxed in xylene and rehydrated through a graded ethanol series. Antigen retrieval was performed by boiling for 10 minutes in $10 \mathrm{mM}$ citric acid buffer, $\mathrm{pH}$ 6.0 in a microwave oven. Endogeneous peroxidase activity was blocked by incubation with $3 \%(\mathrm{v} / \mathrm{v})$ hydrogen peroxide for 10 minutes. Endogenous binding sites were blocked using an avidin/biotin blocking kit (Vector laboratories Inc., California, USA, catalogue number SP-2001) according to the manufacturer's protocol. The TMA was incubated with avidin for 10 minutes and washed twice in TBST wash buffer (0.05 M Tris- $\mathrm{HCl} \mathrm{pH} 7.6,0.3 \mathrm{M} \mathrm{NaCl}$ and $0.1 \%$ Tween 20 ) followed by biotin incubation for 10 minutes.

Immunohistochemistry for Egr-1 was done using a tyramide-based catalyzed signal amplification kit, according to the manufacturer's recommendations (Dako A/S, Denmark, catalogue number K1500). All incubations and washes were done at ambient temperature. The TMA was washed twice in TBST and blocked in protein block for 5 minutes, followed by 15 minutes incubation with antiEgr-1 antibody in antibody diluent (Dako A/S, Denmark, catalogue number S3022). The TMA were washed 3 times in TBST and underwent 5 sequential incubations with $3 \times$ washes in TBST between each step: 15 minutes with biotinylated goat anti-rabbit IgG (diluted in TBST); 15 minutes with streptavidin-biotin complex; 15 minutes with amplification reagent; 15 minutes with streptavidin-peroxidase; and 5 minutes with substrate chromagen solution. Finally, the TMA were rinsed in water, counterstained with Mayer's haematoxylin, dehydrated through ethanol into xylene and mounted in DPX (Fisher Scientific, Loughborough, UK, catalogue number D/5319/05).

The specificity of the rabbit monoclonal antibody used in this study has been evaluated by the use of another polyclonal anti-Egr-1 antibody (SC-189, Santa Cruz Biotechnology), and full agreement between the two was found $[11,19]$ and Egerod et al., 2009, submitted. Furthermore, the observed nuclear localization of Egr-1 was in agreement with that observed by others [20]. Finally, a majority of human prostate cancer cells exhibited strong nuclear Egr-1 immunolabelling, in agreement with the known high expression of Egr-1 in human and mouse prostate cancers [14-17]. No nuclear Egr-1 immunolabelling was found in the negative prostate cancer control where the primary antibody was omitted (figure $1 \mathrm{E}-\mathrm{F}$ ). The positive and negative control followed the same immunostaining procedure as the TMA, with the exception for the negative

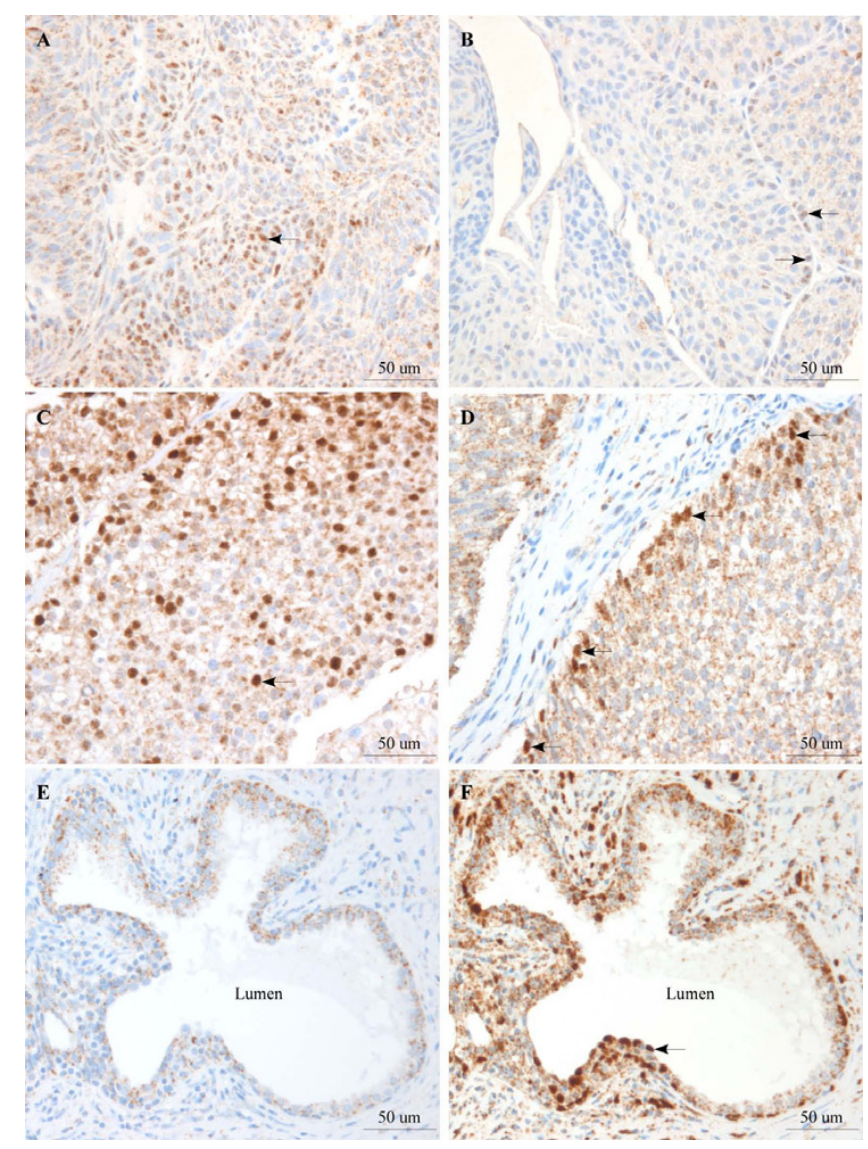

Figure I

Egr-I expression in human bladder cancer and prostate cancer tissue. Expression of Egr-I was examined by immunohistochemistry in human bladder cancer tissue cores arranged on a tissue microarray (A-D), and in prostate cancer tissue $(E, F)$. E, negative control with the primary Egr-I antibody omitted. Arrow, nuclear Egr-I immunolabelling. 
control where the primary anti-Egr-1 antibody was omitted.

\section{Semiquantitation of Egr-I immunolabelling}

Egr-1 immunolabelling was scored (semiquantitatively) by two persons using a double headed microscope, according to predefined scoring criteria (see below). Scoring was blinded to the course of the disease.

Egr-1 nuclear immunolabelling was scored only in tumor cells (based on purely morphological criteria, using only haematoxylin staining, and leaving out small lymphocyte-like cells). Specimens were scored as " 0 " when no nuclear Egr-1 labelling was present, " 1 " when less than $33 \%$ of tumor cell nuclei exhibited Egr-1 immunolabelling, "2" when between $33 \%$ and $67 \%$ of tumor cell nuclei exhibited nuclear Egr-1 immunolabelling, and "3" when over $67 \%$ of the tumor cells exhibited nuclear immunolabelling. The intensity of the nuclear immunolabelling was likewise scored visually in categories, " 1 " for weak nuclear staining intensity, "2" for moderate nuclear staining intensity and "3" for strong nuclear staining intensity.

The reproducibility of the Egr-1 immunolabelling was evaluated by a second score of approximately 30 biopsies randomly chosen from a second TMA stained on a different day. The scores between the two TMAs were identical.

\section{Statistics}

Kruskal-Wallis and Mann Whitney tests were done using GraphPad Prism 5 software (GraphPad Software, Inc., CA, USA). Stata 10.0 statistical analysis software (Stata Corporation, College Station, TX, USA) was used for calculation of Log-rank tests for equality of survival function, KaplanMeier survival plots, and univariate and multivariate Cox regression analysis. Variables with a P value $<0.01$ in univariate analysis were included in multivariate analysis to identify variables with independent significance. The assumptions of proportional hazards were verified.

\section{Results}

Of the 289 tissue cores on the TMA, some tissue cores were missing, likely due to loss during sectioning or antigen retrieval. In total 244 tissue cores (158 Ta tumors, 84 T1 tumors and 2 CIS lesions) were scored for Egr-1 protein expression (table 1). The 2 CIS lesions represented on the TMA were too few for statistical analysis. Only 5 tissue cores were scored as category 3 (high Egr-1 score), and consequently, in order to perform statistical analysis the two Egr-1 scores of 2 and 3, were combined in one group.

\section{Egr-I expression levels in relation to patient and tumor characteristics}

Egr-1 expression in 244 tumors was compared to clinical and histopathological characteristics. The frequency and number of Egr-1 positive tumors are listed in table 1 . We found that Egr-1 expression was correlated to tumor stage, stage T1 tumors exhibited significantly higher levels of Egr-1 positive tumor cells than Ta tumors $(P=0.001$, Mann Whitney test). Egr-1 expression levels were also significantly correlated to the tumor growth patterns. The highest Egr-1 expression was found in tumors showing both solid and papillary growth, and lowest expression was observed in solid tumors $(P=0.033$, Kruskal-Walis test). Finally, we found that Egr-1 expression was significantly correlated to tumor grade. The high grade tumors showed significantly higher levels of Egr-1 positive tumor cells compared to low grade tumors or PUNLMP (papillary urothelial neoplasm of low malignant potential) $(\mathrm{P}<$ 0.001 , Kruskal-Walis test). There were no significant differences in Egr-1 expression when comparing sex or tumor size.

\section{Correlation between Egr-I expression levels and progression free survival}

Kaplan-Meier survival statistics showed that tumors with high percentages of Egr-1 positive tumor nuclei had a significantly higher risk of progression to stage T2-4 (logrank test, $\mathrm{P}=0.035$, figure 2 ). The survival curves presented in figure 2 suggest that patients with lack of Egr-1 protein in the cancer cells constitute a seperat subpopulation with a more favourable prognosis than patients with either low, moderate or high Egr-1 protein expression. Indeed separating the patients into only two groups (no Egr-1 versus Egr-1 protein) resulted in significant different prognosis for the two groups $(\mathrm{P}=0.014)$ (not shown).

The associations between patient age, sex, stage, grade, tumor size, treatment, concomitant CIS, tumor type and Egr-1 protein expression with progression to T2-T4 invasive tumors were tested by univariate Cox regression analysis (table 2). In the univariate analysis Egr-1, patient age, tumor type, tumor stage and tumor grade showed a significant association with progression to T2-T4. Risk factors that were significant $(\mathrm{P}<0.01)$ in the univariate analysis were included in the multivariate analysis. However in the multivariate analysis, Egr-1 expression levels did not prove to be an independent variable for predicting progression to T2-T4 (table 2).

\section{Egr-I expression localization and intensity of immunolabelling}

In some cases, tumor cells with nuclear Egr-1 immunolabelling were found to localize predominantly at the tumor front, i.e. at the border between the bladder tumor and the normal bladder stromal cells (figure 1D). The apparent preponderance of Egr-1 labelling at the tumor front was not found in all specimens. In some cases, tumor cells with nuclear Egr-1 immunolabelling were also found relatively evenly distributed throughout the tumor tissue as 
Table I: Patient and tumor characteristics

\begin{tabular}{|c|c|c|c|c|}
\hline Characteristics & Number ${ }^{\mathrm{a}}$ & Number Egr-I positive biopsies & Percent Egr-I positive biopsies & $\mathbf{P}$ \\
\hline All patients & 244 & & & \\
\hline \multicolumn{5}{|l|}{ Sex } \\
\hline Male & 193 & 109 & 56.2 & $0.882^{d}$ \\
\hline Women & 51 & 28 & 54.9 & \\
\hline \multicolumn{5}{|l|}{ Tumor size } \\
\hline$<3 \mathrm{~cm}$ & 153 & 81 & 52.9 & $0.282^{d}$ \\
\hline$>3 \mathrm{~cm}$ & 63 & 40 & 63.5 & \\
\hline \multicolumn{5}{|l|}{ Tumor type } \\
\hline Papillary & 213 & 118 & 55.4 & $0.033^{e}$ \\
\hline Solid & 16 & 7 & 43.8 & \\
\hline Mixed & 13 & 12 & 92.3 & \\
\hline \multicolumn{5}{|l|}{ Tumor stage } \\
\hline $\mathrm{Ta}$ & 158 & 79 & 50.0 & $0.00 I^{d}$ \\
\hline $\mathrm{TI}$ & 84 & 58 & 69.0 & \\
\hline CISb & 2 & 0 & & \\
\hline \multicolumn{5}{|l|}{ Histological grade } \\
\hline PUNLMPc + Low grade & 158 & 78 & 49.4 & $<0.001^{d}$ \\
\hline High grade & 83 & 58 & 69.9 & \\
\hline
\end{tabular}

a Of the 289 biopsies on the TMA, analysis was only possible of 244 biopsies

bExcluded from analysis (too few represented)

cPapillary urothelial neoplasm of low malignant potential

dMann Whitney test

eKruskal-Wallis test.

illustrated in figure 1 A-C. No statistically significant difference was found in the intensity of Egr-1 nuclear immunolabeling between the Ta tumors and T1 tumors $(\mathrm{P}=$ 0.124 , not shown).

\section{Egr-I expression in non-tumorigenic bladder tissue}

The urothelium in three bladder specimens from nontumorigenic human bladder tissue were examined for Egr1 immunolabelling. No Egr-1 positive nuclei were found in the urothelium (not shown).

\section{Discussion}

A role for Egr-1 in human bladder cancer progression would be expected from the fact that Egr-1 regulates heparanase and HYAL-1 hyaluronidase expression in human bladder cancer cells [8,9]. In bladder cancer cells upregulation of heparanase expression is shown to occur in a stepwise manner where hypomethylation of the heparanase gene promoter facilitates Egr-1 binding, which is shown to directly regulate the heparanase expression [8]. Heparanase plays a critical role in the degradation of the extracellular matrix and the basement membranes and overexpression is correlated with increased metastatic potential and thereby worse prognosis [21]. Heparanase expression has been found upregulated in gastric, pancreatic, melanoma, prostate and bladder cancers [21-25]. 


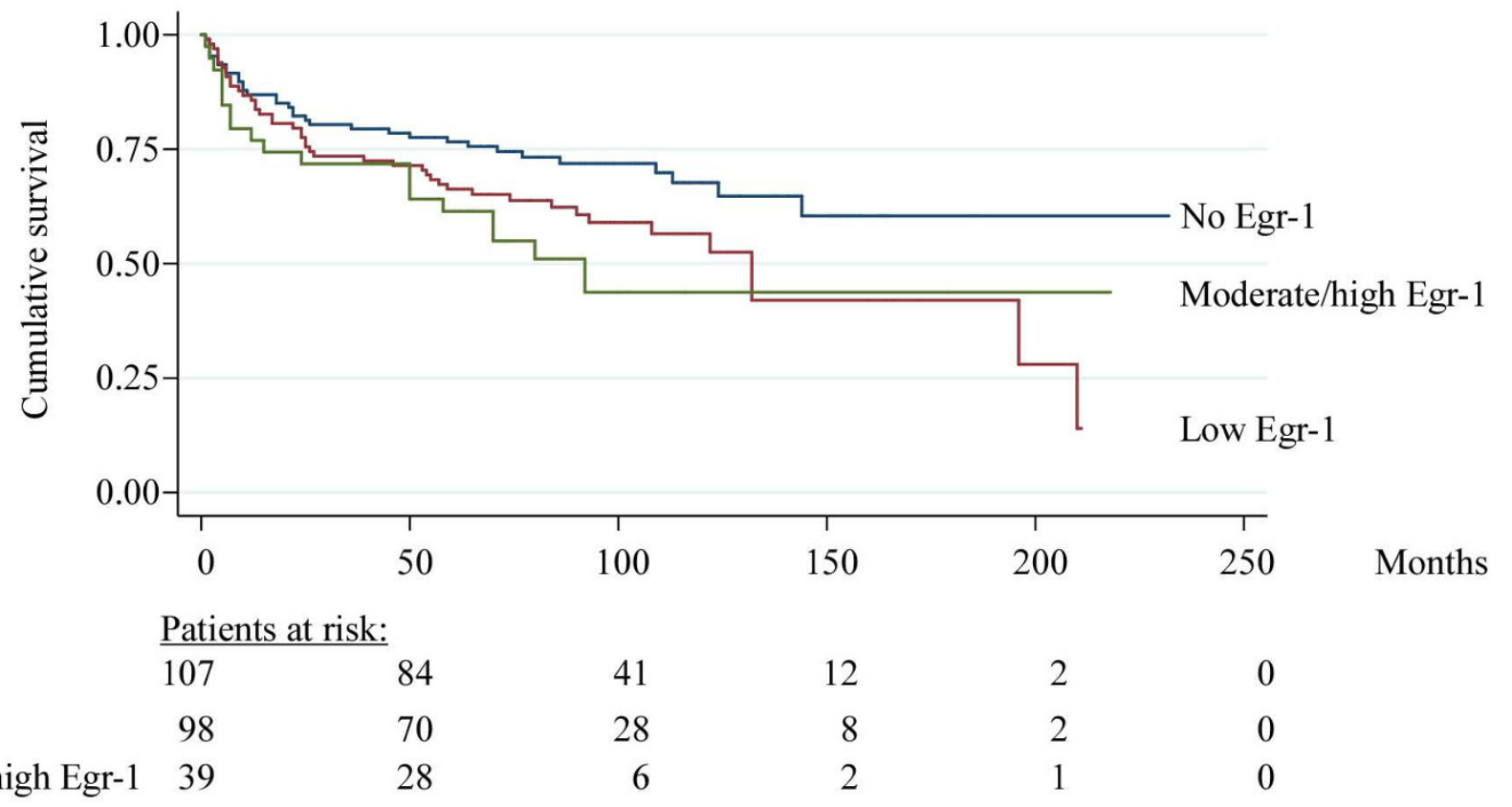

\section{Figure 2}

Kaplan-Meier plot. Kaplan-Meier survival curve illustrating correlation between Egr-I score (frequency of Egr-I positive cancer cell nuclei in tumor mass) and progression to stage T2-T4 bladder cancer. Information from 244 patients was included. P= 0.035, log rank test. Total number of events were 96, with 33 events in Egr-I negative, 44 events in low Egr-I and 19 invents in moderate/high Egr-I.

Also the HYAL-1 hyaluronidase expression in bladder cancer has been suggested to be regulated by binding of Egr1 to the methylated promoter of HYAL-1 hyaluronidase [9].

Hyaluronidase is a highly sensitive and specific marker for high-grade bladder cancer and elevated levels have also been shown in prostate, head, neck and breast cancers and in malignant glioma [9,26-29]. Hyaluronidases degrades hyaluronic acid, which also serves as a tumor marker and promotes metastasis $[4,6,29,30]$.

While heparanase expression was not found in normal bladder tissue, low HYAL-1 hyaluronidase expression was found in normal bladder tissue compared to tumor tissue $[8,9]$. In the present study, we did not find Egr-1 expression in the three normal human bladder specimens examined (not shown), further supporting a possible role for Egr-1 in human bladder carcinogenesis. Likewise, we previously found that normal rat bladder urothelium expresses no or low levels of Egr-1 [11,19] and Egerod et al., 2009, submitted.

Egr-1 has been shown to regulate the transformation to invasive carcinoma in prostate cancer tumorigenesis, where Egr-1 deficient mice display impaired tumorigene- sis [14]. Also inhibition of Egr-1 by antisense oligonucleotides reversed transformation of prostate cancer cells in vitro and in vivo [31].

Because bladder and prostate cancer co-occurs in some patients, it has been suggested that these 2 cancer forms share a common molecular mechanism [32]. The mechanism behind Egr-1 expression in both bladder and prostate cancer are unexplored, but potent inducers of Egr-1 could be stimuli present in tumors in vivo such as hypoxia, growth factors and inflammation. One of the clinical implications of our study is that it indirectly supports that the molecular mechanisms underlying bladder and prostate cancer may be similar. Another implication of our study is that it opens new avenues for determining the molecular mechanisms underlying bladder cancer. By performing chromatin immunoprecipitation experiments with Egr-1 antibodies, it may be feasible to determine genes regulated by Egr-1 in invasive human bladder tumor specimens. This would have long-term clinical implications for diagnosis as well as treatment of bladder cancer.

Our study strengthens the role of Egr- 1 as a mediator of transformation to invasive bladder cancers. In the univariate analysis Egr-1 was significantly associated with pro- 
Table 2: Univariate and multivariate COX regression analysis

\begin{tabular}{|c|c|c|c|c|}
\hline \multirow[b]{2}{*}{ Factor } & \multicolumn{2}{|c|}{ Univariate analysis } & \multicolumn{2}{|c|}{ Multivariate analysis $^{\mathrm{a}}$} \\
\hline & Hazard ratio ${ }^{b}$ & $\mathbf{P}$ & Hazard ratio ${ }^{b}$ & $\mathbf{P}$ \\
\hline \multicolumn{5}{|l|}{ Egr-I } \\
\hline Low expression (score I) versus Egr-I negative (score 0 ) & $1.59(1.01-2.50)$ & 0.044 & I.4I (0.89-2.24) & 0.143 \\
\hline Moderate-high expression (score 2-3) versus Egr-I negative (score 0) & $1.95(1.11-3.44)$ & 0.021 & $1.38(0.76-2.49)$ & 0.285 \\
\hline Age (5 year intervals) & $1.19(1.08-1.31)$ & 0.001 & I.II (0.99-1.25) & 0.078 \\
\hline Tumor type (Papillary versus solid/mixed) & $2.33(1.43-3.80)$ & 0.001 & $1.78(1.03-3.08)$ & 0.038 \\
\hline Tumor stage ( $\mathrm{TI}$ versus $\mathrm{Ta}$ ) & $3.01(2.07-4.38)$ & $<0.001$ & $0.42(0.16-1.10)$ & 0.078 \\
\hline Tumor grade (High grade versus PUNLMP+low grade) & $3.42(2.34-4.98)$ & $<0.001$ & $6.12(2.27-16.55)$ & 0.000 \\
\hline Sex & $0.99(0.63-1.56)$ & 0.981 & & \\
\hline Size $(>3 \mathrm{~cm}$ versus $<3 \mathrm{~cm})$ & $1.02(0.65-1.60)$ & $0.94 I$ & & \\
\hline Bacillus Calmette-Guerin (BCG) treatment & $0.55(0.32-0.93)$ & 0.026 & & \\
\hline Concomitant CIS & $1.02(0.65-1.60)$ & 0.941 & & \\
\hline
\end{tabular}

aOnly risk factors that were significant $(P<0.01)$ in the univariate analysis was included in the multivariate analysis.

bNumber in parentheses, $95 \%$ confidence intervals.

gression to T2-T4; however this was not the case in the multivariante analysis. Therefore Egr-1 cannot be considered an independent marker for progression to T2-T4. Nevertheless, in our study, Egr-1 was still found associated with tumor stage, tumor grade and progression to invasive tumors. Furthermore, we know from previous gene expression studies that Egr-1 is over expressed in muscle invasive tumors. This also emphasizes that Egr-1 may play a role in tumor progression.

CIS is often associated with a high risk of disease progression. Unfortunately, this study included very few CIS lesions, and consequently further work is needed to examine to what extent Egr-1 is expressed in CIS lesions.

\section{Conclusion}

Our study supports a role of Egr-1 in the early steps of human bladder carcinogenesis, with progression from non-muscle invasive tumors to muscle invasive cancers, and emphasizes the need for more comprehensive studies to explore the involvement of Egr-1 in human bladder cancer.

\section{Competing interests}

The authors declare that they have no competing interests.

\section{Authors' contributions}

FLE carried out the immunohistochemical analyses, performed data analysis and part of the statistical analyses, interpretation of data, and drafted the manuscript. $\mathrm{AB}$ scored the tissue microarray. NF constructed the tissue microarray and collected follow-up information for all patients in collaboration with $\mathrm{LD}, \mathrm{MB}$ and TFØ. MBO and NB participated in the conception and design of the study, and critically revised the manuscript. LD performed data analysis and part of the statistical analyses, interpretation of data and critically revised the manuscript. All authors read and approved the final manuscript.

\section{References}

I. Ferlay ]: Estimates of the worldwide mortality from 25 cancers in 1990. International Journal of Cancer 1999, 83:18-29.

2. Dyrskjøt L, Zieger K, Kruhøffer M, Thykjaer T, Jensen JL, Primdahl H, et al: A molecular signature in superficial bladder carcinoma predicts clinical outcome. Clin Cancer Res 2005, I I:4029-4036.

3. Barboro P, Rubagotti A, Orecchia P, Spina B, Truini M, Repaci E, et al.: Differential proteomic analysis of nuclear matrix in muscleinvasive bladder cancer: potential to improve diagnosis and prognosis. Cell Oncol 2008, 30:13-26.

4. Mohammed A, Khan Z, Zamora I, Bhatti A: Biological markers in the diagnosis of recurrent bladder cancer: an overview. Expert Rev Mol Diagn 2008, 8:63-72.

5. Pitts WR: Predicting outcome in minimally invasive ( $\mathrm{Tla}$ and TIb) urothelial bladder cancer using a panel of biomarkers: a high-throughput tissue microarray analysis. BJU Int 2008, 101:1595. 
6. Vrooman OP, Witjes JA: Molecular markers for detection, surveillance and prognostication of bladder cancer. Int J Urol 2009, 16:234-243.

7. Nutt JE, Foster PA, Mellon JK, Lunec J: hEGRI is induced by EGF, inhibited by gefitinib in bladder cell lines and related to EGF receptor levels in bladder tumours. $\mathrm{Br} J$ Cancer 2007 96:762-768.

8. Ogishima T, Shiina H, Breault JE, Terashima M, Honda S, Enokida H, et al.: Promoter $\mathrm{CpG}$ hypomethylation and transcription factor EGRI hyperactivate heparanase expression in bladder cancer. Oncogene 2005, 24:6765-6772.

9. Lokeshwar VB, Gomez P, Kramer M, Knapp J, McCornack MA, Lopez LE, et al.: Epigenetic regulation of HYAL-I hyaluronidase expression. identification of HYAL-I promoter. J Biol Chem 2008, 283:29215-29227.

10. Ogishima T, Shiina H, Breault JE, Tabatabai L, Bassett WW, Enokida $\mathrm{H}$, et al.: Increased heparanase expression is caused by promoter hypomethylation and up-regulation of transcriptiona factor early growth response- $I$ in human prostate cancer. Clin Cancer Res 2005, I I: I028-1036.

II. Egerod FL, Nielsen HS, Iversen L, Thorup I, Storgaard T, Oleksiewicz MB: Biomarkers for early effects of carcinogenic dual-acting PPAR agonists in rat urinary bladder urothelium in vivo. Biomarkers 2005, 10:295-309.

12. Popov Z, Gil-Diez-de-Medina S, Ravery V, Hoznek A, Bastuji-Garin S, Lefrere-Belda M, et al.: Prognostic value of EGF receptor and tumor cell proliferation in bladder cancer: therapeutic implications. Urologic oncology 2004, 22:93-101.

13. McShane LM, Altman DG, Sauerbrei W, Taube SE, Gion M, Clark GM, et al:: REporting recommendations for tumour MARKer prognostic studies (REMARK). Br J Cancer 2005, 93:387-39I.

14. Abdulkadir SA, Qu Z, Garabedian E, Song SK, Peters TJ, Svaren J, et al:: Impaired prostate tumorigenesis in Egrl-deficient mice. Nat Med 200I, 7:101-107.

15. Virolle T, Krones-Herzig A, Baron V, De GG, Adamson ED, Mercola $D$ : Egrl promotes growth and survival of prostate cancer cells. Identification of novel Egr I target genes. I Biol Chem 2003, 278: II802-II8I0

16. Adamson ED, Mercola D: EgrI transcription factor: multiple roles in prostate tumor cell growth and survival. Tumour Biol 2002, 23:93-102.

17. Eid MA, Kumar MV, Iczkowski KA, Bostwick DG, Tindall DJ: Expression of early growth response genes in human prostate cancer. Cancer Res 1998, 58:246I-2468.

18. Kononen J, Bubendorf L, Kallioniemi A, Bärlund M, Schraml P, Leighton $S$, et al:: Tissue microarrays for high-throughput molecular profiling of tumor specimens. Nat Med 1998, 4:844-847.

19. Egerod FL, Brünner N, Svendsen JE, Oleksiewicz MB: PPARalpha and PPARgamma are co-expressed, functional and show positive interactions in the rat urinary bladder urothelium. Journal of Applied Toxicology 2009 in press.

20. Knight C, Slade JP, Carter D: The nuclear, 75 kDa form of early growth response protein-1/nerve growth factor-induced $A$ protein is primarily restricted to $\mathrm{LH}$ beta-subunit-expressing cells in rat anterior pituitary. Eur J Endocrinol 2000, 143:8I7-82I.

2I. Gohji K, Hirano H, Okamoto M, Kitazawa S, Toyoshima M, Dong J, et al.: Expression of three extracellular matrix degradative enzymes in bladder cancer. Int / Cancer 200 I:295-30I.

22. Takaoka M, Naomoto $Y$, Ohkawa T, Uetsuka H, Shirakawa $Y$, Uno F et al: Heparanase expression correlates with invasion and poor prognosis in gastric cancers. Lab Invest 2003, 83:6I3-622.

23. Koliopanos A, Friess $H$, Kleeff J, Shi X, Liao Q, Pecker I, et al.: Heparanase expression in primary and metastatic pancreatic cancer. Cancer Res 200I, 6 I:4655-4659.

24. Marchetti D, McQuillan DJ, Spohn WC, Carson DD, Nicolson GL: Neurotrophin stimulation of human melanoma cell invasion: selected enhancement of heparanase activity and heparanase degradation of specific heparan sulfate subpopulations. Cancer Res 1996, 56:2856-2863.

25. Kosir MA, Quinn CC, Zukowski KL, Grignon DJ, Ledbetter S: Human prostate carcinoma cells produce extracellular heparanase. J Surg Res 1997, 67:98-105.

26. Kramer MW, Golshani R, Merseburger AS, Knapp J, Garcia A, Hennenlotter J, et al.: HYAL-I Hyaluronidase: A Potential Prognos- tic Indicator for Progression to Muscle Invasion and Recurrence in Bladder Cancer. European Urology 2009 in press.

27. Lokeshwar VB, Cerwinka WH, Isoyama T, Lokeshwar BL: HYALI hyaluronidase in prostate cancer: a tumor promoter and suppressor. Cancer Res 2005, 65:7782-7789.

28. Lokeshwar VB, Cerwinka WH, Lokeshwar BL: HYALI hyaluronidase: a molecular determinant of bladder tumor growth and invasion. Cancer Res 2005, 65:2243-2250.

29. Lokeshwar VB, Selzer MG: Hyalurondiase: both a tumor promoter and suppressor. Seminars in Cancer Biology 2008, 18:28I-287.

30. Lam T, Nabi G: Potential of urinary biomarkers in early bladder cancer diagnosis. Expert Rev Anticancer Ther 2007, 7:1105-III5.

31. Baron V, De GG, Krones-Herzig A, Virolle T, Calogero A, Urcis R, et al: Inhibition of Egr-I expression reverses transformation of prostate cancer cells in vitro and in vivo. Oncogene 2003, 22:4194-4204.

32. Singh A, Kinoshita Y, Rovito PMJ, Landas S, Silberstein J, Nsouli I, et al: Higher than expected association of clinical prostate and bladder cancers. J Urol 2005, I73:1526-1529.

\section{Pre-publication history}

The pre-publication history for this paper can be accessed here:

http://www.biomedcentral.com/1471-2407/9/385/pre pub
Publish with Bio Med Central and every scientist can read your work free of charge

"BioMed Central will be the most significant development for disseminating the results of biomedical research in our lifetime. "

Sir Paul Nurse, Cancer Research UK

Your research papers will be:

- available free of charge to the entire biomedical community

- peer reviewed and published immediately upon acceptance

- cited in PubMed and archived on PubMed Central

- yours - you keep the copyright 